\title{
Beyond User Acceptance: A Legitimacy Framework for Potable Water Reuse in California
}

\author{
Sasha R. Harris-Lovett,,$^{\dagger, \dagger}$ Christian Binz, ${ }^{\dagger, \S, \#}$ David L. Sedlak, ${ }^{\dagger, \|}$ Michael Kiparsky, ${ }^{\dagger, \perp}$ \\ and Bernhard Truffer ${ }^{\dagger, \S, \nabla}$ \\ ${ }^{\dagger}$ National Science Foundation Engineering Research Center for Re-Inventing the Nation’s Urban Water Infrastructure, \\ ${ }^{\ddagger}$ Energy \& Resources Group, University of California at Berkeley, Berkeley, California 94720, United States \\ ${ }^{\S}$ Department of Environmental Social Sciences Eawag: Swiss Federal Institute of Aquatic Science and Technology 8600 Dübendorf, \\ Switzerland \\ "Department of Civil \& Environmental Engineering, University of California at Berkeley, Berkeley, California 94720, United States \\ ${ }^{\perp}$ Wheeler Institute for Water Law \& Policy, University of California at Berkeley, School of Law, Berkeley, California 94720-7200, \\ United States \\ \#Sustainability Science Program, Kennedy School of Government, Harvard University, Cambridge, Massachusetts 02138, \\ United States \\ ${ }^{\nabla}$ Chair of Geography of Transitions in Urban Infrastructures, Faculty of Geosciences, University of Utrecht, Heidelberglaan 2 , \\ NL-3584 CS, Utrecht, Netherlands
}

\section{Supporting Information}

\begin{abstract}
Water resource managers often tout the potential of potable water reuse to provide a reliable, local source of drinking water in water-scarce regions. Despite data documenting the ability of advanced treatment technologies to treat municipal wastewater effluent to meet existing drinking water quality standards, many utilities face skepticism from the public about potable water reuse. Prior research on this topic has mainly focused on marketing strategies for garnering public acceptance of the process. This study takes a broader perspective on the adoption of potable water reuse based on concepts of societal legitimacy, which is the generalized perception or assumption that a technology is desirable or appropriate within its social context. To assess why some potable reuse projects were successfully implemented while others faced fierce public opposition, we performed a series of 20 expert interviews and reviewed in-depth case studies from potable reuse projects in California. Results show that proponents of a legitimated potable water reuse project in Orange County, California engaged in a portfolio of strategies that addressed three main dimensions of legitimacy. In contrast, other proposed projects that faced extensive public opposition relied on a smaller set of legitimation strategies that focused near-exclusively on the development of robust water treatment technology. Widespread legitimation of potable water reuse projects, including direct potable water reuse, may require the establishment of a portfolio of standards, procedures, and possibly new institutions.
\end{abstract}

\section{INTRODUCTION}

Limited water resources and increasingly complex societal demands require water managers to develop innovative solutions to water challenges. ${ }^{1}$ However, changing practices in the water sector is notoriously difficult because the social and institutional contexts, including the rules, norms, and conventions that govern decision-making, often hinder diffusion of innovative technologies or new systems of governance. ${ }^{2}$ Water recycling, and in particular recycling for potable water reuse, illustrates the ways in which social and institutional concerns can affect technology adoption. ${ }^{3,4}$ Potable water reuse is defined here as the practice of intentionally returning highly treated municipal wastewater to the public water supply.

Some water resource managers and consulting engineers tout the potential of potable water reuse to provide a local, reliable water supply in water-scarce regions. ${ }^{7-10}$ Potable water reuse can be less costly than alternatives, such as desalination or importing additional water, and can meet or exceed existing water quality standards. ${ }^{5}$ However, these factors are not always sufficient for obtaining public support. ${ }^{11}$ Proponents of potable water reuse have mainly framed this issue as one of a lack of public acceptance, ${ }^{12-14}$ which can be defined as the public's passive acquiescence to the expert knowledge of water managers and engineers. ${ }^{15}$

Previous research has addressed the lack of public acceptance of potable water reuse $\mathrm{e}^{7,10-16}$ by focusing on the benefits of selecting positive terminology to describe the practice, development of communication strategies, characterization of populations that accept potable water reuse, and development of public education campaigns. ${ }^{11,13,16-21}$ This research has yielded an improved

Received: January 28,2015

Revised: May 18, 2015

Accepted: June 1, 2015

Published: June 1, 2015 
understanding of the language and strategies for marketing potable water reuse. Nonetheless, in several high-profile cases, technologically sound potable reuse projects have floundered when actors outside of the control of the project's advocates used terminology that was unfavorable. ${ }^{11}$

Research based on public acceptance does not incorporate the full complexity of the issues surrounding new technology adoption, $^{22}$ and may overestimate the ability of project proponents to affect community support by targeting individual perceptions of water reuse. ${ }^{23}$ Previous studies have shown that water authorities and developers tend to approach public acceptance by attempting to persuade the public to accept water reuse by providing more technical information. This occurs despite evidence that members of the public are interested in a broad range of information about the project including social and environmental costs and benefits, institutional structure, risk comparisons to other activities, regulatory systems, and analysis of alternative solutions. ${ }^{24}$ Previous research suggests a public acceptance paradigm for understanding perceptions of potable water reuse is too narrowly framed, but stops short of proposing an empirically grounded, comprehensive framework. $^{15,25}$ Other scholars place a public acceptance mode of expert outreach for water management, in which experts choose what they perceive as the most desirable solution and convince the community of its relevance and importance, as a hallmark of an old paradigm of unsustainable water systems that is no longer useful in the twenty-first century. ${ }^{26}$

A more robust framework for engaging the public in issues of potable water reuse based on societal legitimacy ${ }^{27}$ may address some of the shortcomings in public acceptance research. Legitimacy-a key concept in sociology and innovation studies-acknowledges that creating widespread trust in an innovation depends on strategies that not only target individual psychology, but that also address aggregate sectorial and societal rules, norms and conventions. ${ }^{29-29}$ Sociology scholars define legitimacy as "a generalized perception or assumption that the actions of an entity are desirable, proper, or appropriate within some socially constructed system of norms, values, beliefs, and definitions". ${ }^{30}$ In its sociological definition, legitimacy can be assessed by the "taken-for-grantedness" of a particular technology, implementing organization, or process. ${ }^{28}$

Establishing legitimacy involves embedding a new technology in the shared social belief systems, moral standards and cultural conventions of a given group, ${ }^{28,31,32}$ through a set of strategies that go beyond traditional public relations or educational outreach. Establishment of legitimacy may require the implementing organizations to undergo fundamental changes. Some of these changes may challenge the traditional authority of water providers, as they may require sharing power through collaborative decision-making and consideration of heterogeneous public values. Water utilities cannot build legitimacy for potable water reuse based on hollow promises. Superficial interventions undertaken to approximate the legitimacy framework presented in this paper and manipulate public perceptions of legitimacy will likely not create stable legitimacy, but rather foster mistrust in the management's true intentions. Because legitimation is a societal process, it is most stable when it is established in public discourse.

It is important to note that establishment of legitimacy for a particular technology, like potable reuse, may not be possible in places where the technology does not mesh with the values and social beliefs of a given community. A deeper understanding of legitimacy and the legitimation process can, however, help water engineers find solutions for water supply and wastewater disposal that are most appropriate for a given community. It can also help prevent investment in technological infrastructure that will encounter stark public opposition.

The case of potable water reuse in California illustrates the process of legitimation, which has relevance to a wide range of emerging environmental technologies. California has a long history of potable reuse, ${ }^{33}$ from which we draw and examine examples of both successful and unsuccessful attempts to legitimize the practice. We extend the sociological definitions of legitimacy to include innovative technologies and the institutional systems surrounding them ${ }^{27}$ and define a comprehensive analytical framework for the legitimation process of potable water reuse and innovations in general (see Table 1). The present paper complements another publication (Binz et al., submitted), which focuses on a detailed process account of technology legitimation in an innovation system context. ${ }^{3}$

\section{ANALYTICAL FRAMEWORK FOR LEGITIMACY}

Legitimacy is a multidimensional phenomenon that can be differentiated into several key types. Suchman's comprehensive framework (1995) divides legitimacy into three generic types: pragmatic, moral and cognitive, ${ }^{28}$ which we term Type 1 , Type 2, and Type 3 legitimacy, respectively. Each of these types can be further grouped into several distinct dimensions. Table 1 illustrates our application of legitimacy concepts to innovative technologies in general and potable reuse in particular.

Pragmatic Legitimacy (Type 1 Legitimacy) is based on the end user's self-interested calculations about the direct benefits that can be derived from the innovation. ${ }^{28}$ Its first component, exchange legitimacy, is derived from the end user's perceived gain of a good or service from the innovation (e.g., support for a water reuse project based on the notion that adoption of the technology may provide a means for maintaining golf courses without restrictions on water use). The second component is influence legitimacy, which occurs when end users perceive an implementing organization to be responding directly to their personal interests $^{28}$ (e.g., support of a potable reuse project arising from the participation of community members on the project's advisory board). The third component, dispositional legitimacy, occurs when an innovation is managed by an established, trustworthy entity (e.g., faith in a water utility with a professional reputation to responsibly manage a potable reuse project).

Moral Legitimacy (Type $\mathbf{2}$ Legitimacy) is established when an innovation corresponds to societal values and broader societal welfare. ${ }^{28}$ The first component, consequential legitimacy, occurs when proponents of an innovation demonstrate that it has a strong record of providing beneficial outcomes for society (e.g., support for potable water reuse systems that have operated for a long time without problems). The second component, procedural legitimacy, is defined by the quality and validity of the procedures and protocols used to implement the innovation (e.g., trust in potable water reuse systems based on end user's awareness of consistent, comprehensive water quality monitoring). The third dimension, structural legitimacy, is related to the physical attributes of the innovation that enhance its safety and reliability (e.g., endorsement of a reuse project based on the presence of a state-of-the-art water quality lab). The final component of Type 2 legitimacy, personal legitimacy, is related to the perceived trustworthiness and integrity of the implementing organization's leadership. 
Table 1. Definitions of Key Dimensions of Legitimacy and Corresponding Strategies in Potable Reuse (Source: Adapted from Suchman (1995))

\begin{tabular}{|c|c|c|c|}
\hline legitimacy types & dimension & definition & legitimation strategies in potable water reuse \\
\hline \multirow[t]{3}{*}{$\begin{array}{l}\text { Type 1. pragmatic evaluation } \\
\text { based on self- interest }\end{array}$} & 1.1 exchange & $\begin{array}{l}\text { support for an innovation based on its perceived } \\
\text { value to the end user }\end{array}$ & $\begin{array}{l}\text { public outreach campaigns, explaining the innovation's } \\
\text { benefits to different users }\end{array}$ \\
\hline & 1.2 influence & $\begin{array}{l}\text { support of an implementing organization because it } \\
\text { shares decision-making power with end users }\end{array}$ & $\begin{array}{l}\text { user involvement in planning and management, focus } \\
\text { groups and surveys, user representatives on decision- } \\
\text { making bodies }\end{array}$ \\
\hline & 1.3 dispositional & $\begin{array}{l}\text { support for an implementing organization based on } \\
\text { a belief that the organization is acting in the end } \\
\text { user's best interest, has "good character" }\end{array}$ & $\begin{array}{l}\text { transparent information policies, cooperation with } \\
\text { external evaluators and regulators, developing a } \\
\text { "quality brand" for the proponent utility }\end{array}$ \\
\hline \multirow{4}{*}{$\begin{array}{l}\text { Type } 2 \text {. moral evaluation } \\
\text { based on norms/societal } \\
\text { values }\end{array}$} & 2.1 consequential & $\begin{array}{l}\text { support based on evaluation of the implementing } \\
\text { organization's accomplishments }\end{array}$ & $\begin{array}{l}\text { publicizing data indicating consistently high water } \\
\text { quality, building a success story about the innovation }\end{array}$ \\
\hline & 2.2 procedural & $\begin{array}{l}\text { support based on an evaluation of the implementing } \\
\text { organization's specific procedures }\end{array}$ & $\begin{array}{l}\text { adopting strict quality control and monitoring } \\
\text { procedures, standardized emergency intervention } \\
\text { plans, and professional training for operators }\end{array}$ \\
\hline & 2.3 structural & $\begin{array}{l}\text { support based on an evaluation of the implementing } \\
\text { organization's physical characteristics }\end{array}$ & $\begin{array}{l}\text { having advanced water treatment technology, water } \\
\text { quality management department, } 24 / 7 \text { monitoring } \\
\text { technology, and emergency shut-off valves }\end{array}$ \\
\hline & 2.4 personal & $\begin{array}{l}\text { support based on an evaluation of an implementing } \\
\text { manager's charisma }\end{array}$ & water utility managers talking directly to the end users \\
\hline \multirow{2}{*}{$\begin{array}{l}\text { Type 3. cognitive evaluation } \\
\text { based on deeply held } \\
\text { customs and beliefs }\end{array}$} & 3.1 comprehensibility & $\begin{array}{l}\text { support because an innovation meshes with the end } \\
\text { user's daily life experiences and cognitive frames }\end{array}$ & $\begin{array}{l}\text { organizing water tastings, providing bottled recycled } \\
\text { water, developing comprehensible vocabulary }\end{array}$ \\
\hline & $\begin{array}{l}3.2 \text { taken-for- } \\
\text { grantedness }\end{array}$ & $\begin{array}{l}\text { support based on seeming inevitability, in which } \\
\text { alternatives are "unthinkable" }\end{array}$ & $\begin{array}{l}\text { relating potable reuse to other taken-for-granted } \\
\text { activities (e.g., recycling) }\end{array}$ \\
\hline
\end{tabular}

Cognitive Legitimacy (Type 3 Legitimacy) is not based on conscious evaluation, but rather on compliance with takenfor-granted routines and cultural beliefs ("the way we do things"). ${ }^{28,31}$ It includes two main components: The first, comprehensibility, occurs if an innovation fits into prevailing cultural assumptions and daily life habits of end users (e.g., support for bottled recycled water if it looks and tastes like established bottled water brands). The second component, taken-for-grantedness, occurs when the innovation meshes with end users' deep cognitive frames that are not consciously questioned (e.g., people familiar with solid waste recycling may think of potable water reuse as another desirable form of recycling).

An innovation is considered wholly legitimized when a majority of the population takes it for granted, and any opponents are no longer able to achieve a serious response from community members. Nonetheless, individual projects may lose credibility even after legitimacy is established for the sector if they do not continue to employ legitimation strategies for their specific project. $^{28}$

Achieving legitimacy for new technologies requires development of all three types of legitimacy: if only Type 1 legitimacy is established, as is often done in acceptance-based public outreach campaigns, the project might be accepted temporarily, but legitimacy will likely erode when end users start questioning whether or not the Type 2-related procedures and institutional structures that support the innovation are legitimate. Similarly, if only Type 2 legitimacy is emphasized, the public may trust that the innovation is managed with competency, but end users may question the usefulness of the innovation to the community. Complete legitimacy thus requires a comprehensive portfolio of legitimation strategies that address each of these dimensions.

We hypothesized that the more complete the legitimation portfolio of a utility involved in potable water reuse projects, the more likely the project will be to avoid organized public opposition or rejection by the community. We assessed the legitimation portfolio of California's potable water reuse projects-and identified gaps therein-to provide insight into the ways in which communities support or reject technological innovation in the water sector.

\section{MATERIALS AND METHODS}

To address the legitimacy of potable water reuse we examined a case study of legitimated potable reuse, and compared it with cases of several other projects in which California water utilities failed to implement potable water reuse.

The Orange County Water District (OCWD), in Orange County, California, was chosen as a case of legitimate potable water reuse. The water district has practiced potable water reuse since 1976, when it began to inject highly treated municipal wastewater into the region's groundwater aquifer. ${ }^{33-36}$ This system was expanded from 15 MGD (57000 $\mathrm{m}^{3} /$ day) to 70 MGD $\left(265000 \mathrm{~m}^{3} /\right.$ day) in 2008. The present advanced treatment system configuration, called the Groundwater Replenishment System (GWRS), sources municipal effluent from a nearby wastewater treatment plant, then uses microfiltration, reverse osmosis, and an advanced oxidation process to further treat the water. The treated water is then pumped into recharge basins and injection wells, where it mixes with local groundwater. ${ }^{37}$ The GWRS contributes to drinking water supplies for more than 2 million people. ${ }^{37}$ There has been no organized public opposition to GWRS (Interview 19). The GWRS is considered a best practice in the potable water reuse community and serves as the basis for the technological design of several other potable water reuse projects. ${ }^{3}$

Other cases considered include the Dublin-San Ramon Services District's proposed potable reuse project, which failed due to public opposition after the facility was built; San Diego's water recycling project, which the public vehemently opposed in the 1990s; and the Santa Clara Valley Water District's proposed potable water reuse project.

We conducted in-depth semistructured interviews with 20 key, expert stakeholders who were deeply involved with implementing potable water reuse in California (as well as nationally and globally). Interviewees included managers and executives of water and wastewater utilities, public relations consultants, 
regulators, academics, and engineering consultants. We used respondent-driven sampling techniques, ${ }^{38}$ including snowball sampling, ${ }^{39}$ to identify and interview the small group of people who have been most influential in the development of potable water reuse systems in California. We designed interview questions to elicit responses about the legitimation strategies applied in single projects as well as in the wider potable water reuse community (see Supporting Information, section 1). We transcribed interviews, then codified them using MaxQDA qualitative data analysis software and analyzed them for mentions or allusions to dimensions of legitimacy. We triangulated interview data with relevant reports and white papers, utility public outreach information, scientific publications, and newspaper articles (see Supporting Information, section 2). We grounded the case studies in historical research regarding local experiences with and attitudes toward water use and reuse. We used perspectives presented in local news articles and editorials as well as the presence or absence of organized public opposition groups as proxy measures for user opinion. ${ }^{40}$ Both are standard proxy measures for user legitimacy in institutional sociology literature (see e.g., Geels and Verhees 2011). ${ }^{41}$ Cases like San Diego where several end-user driven opposition groups and intense, controversial newspaper coverage emerged, indicate limited societal legitimacy. Cases like Orange County that never triggered organized public opposition and mostly positive newspaper coverage, would in turn indicate stable end user legitimacy. These measures were used because many of the cases occurred in the past, so it was not possible to interview users directly.

\section{RESULTS}

Orange County Water District's Potable Water Reuse Program. Since it began its first potable water reuse program in 1976, OCWD has employed a diverse portfolio of legitimation strategies. Some of these strategies were deliberate attempts to foster trust in potable reuse, while others emerged during the development of their potable water reuse system. Each dimension of the project's legitimation portfolio is summarized below and in Table 2 .

Table 2. Summary of OCWD's Legitimacy Portfolio for Potable Reuse ${ }^{a}$

\begin{tabular}{|c|c|c|}
\hline legitimacy type & dimension & strategies \\
\hline \multirow[t]{3}{*}{ Type 1: pragmatic } & 1.1 exchange & $\begin{array}{l}+ \text { targeted outreach and education } \\
\text { campaigns }\end{array}$ \\
\hline & 1.2 influence & $\begin{array}{l}+ \text { elicited feedback from } \\
\text { community leaders }\end{array}$ \\
\hline & 1.3 dispositional & $\begin{array}{l}+ \text { demonstrated the utility's } \\
\text { trustworthiness }\end{array}$ \\
\hline \multirow[t]{4}{*}{ Type 2: moral } & 2.1 consequential & $\begin{array}{l}+ \text { consistent track record of high } \\
\text { water quality }\end{array}$ \\
\hline & 2.2 procedural & $\begin{array}{l}+ \text { emergency intervention and } \\
\text { quality monitoring plans }\end{array}$ \\
\hline & 2.3 structural & $\begin{array}{l}\text { + state-of-the-art technology, } \\
\text { sophisticated laboratory }\end{array}$ \\
\hline & 2.4 personal & $\begin{array}{l}+ \text { management personally involved } \\
\text { in outreach work }\end{array}$ \\
\hline \multirow[t]{2}{*}{ Type 3: cognitive } & $\begin{array}{l}3.1 \\
\quad \text { comprehensibility }\end{array}$ & $\begin{array}{l}+ \text { serving visitors purified water } \\
\text { from a tap }\end{array}$ \\
\hline & $\begin{array}{l}3.2 \text { taken-for } \\
\text { grantedness }\end{array}$ & $\begin{array}{l}+ \text { framing potable reuse as } \\
\text { recycling, groundwater protection }\end{array}$ \\
\hline
\end{tabular}

$a_{+}$traits contributing to legitimacy portfolio, - traits detracting from legitimacy portfolio.
Type 1. Pragmatic Legitimacy. OCWD's management team invested considerable time and resources into explaining how potable water reuse was in the public's best interest (Interview 17), which resulted in the creation of exchange legitimacy for the GWRS. The utility targeted community and business group leaders within their 2.4 million customer service area and informed them about the benefits of the potable water reuse system in simple language (Interview 4) with more than 1200 presentations (Interview 19) that were translated in Spanish, Vietnamese, and Chinese (Interview 17). The talks were targeted to the interests of their specific audience, and emphasized the idea that the technology would guarantee a safe, reliable water supply into the future, which was a key interest of all inhabitants of Orange County (Interview 19).

"We would just go out and talk about what the water district does, what the need was for future needs. And how this project, the Groundwater Replenishment System, meets those needs." (Interview 17)

OCWD established influence legitimacy by soliciting and accepting feedback from the public through citizen's advisory committees, focus groups and in discussions with community leaders (Interview 16). OCWD relied on the citizen's advisory committees to inform certain aspects of the project, including improvement of the project's outreach materials:

"We had a Citizens' Advisory Group, made up of community leaders... So all of these different groups were working together to make sure that needs were met, that we were on point, that we were spending money wisely, and that we were meeting the needs of the community." (Interview 17)

While OCWD carefully planned the above legitimation strategies, others emerged as a result of the district's responses to technical challenges. In particular, in the year 2000, OCWD detected $\mathrm{N}$-nitrosodimethylamine (NDMA), a potent carcinogen, in their treated water, ${ }^{42}$ and realized that some of this compound had actually been created in their water treatment process. Though this situation could have threatened the legitimacy of OCWD's potable reuse efforts (Interview 6), the response of the utility to the incident ultimately enhanced its dispositional legitimacy: Instead of hiding the problem, the management decided to publicly disclose it, and proved to both regulators and the public that they were competent in dealing effectively with the contamination (Interview 5).

"We were actually causing the problem in the water we were injecting. Some of us on the water quality end of the business wanted to get answers to the problem. See what can we do to fix it, first. [The public relations specialist] said no, that we needed to talk to the public, we needed to actually call the media in and do press briefings... His instincts were right. If the media and the public perceive you as having nothing to hide, if you've got something that goes wrong, you're going to tell them about it. [...] I think that really earned us a lot of trust." (Interview 19)

In a press conference, OCWD representatives explained what had happened and how they were working to address the problem. They also set the NDMA exposure in context by explaining how people are routinely exposed to the compound in food and beverages (Interview 17).

As a result of the utility's transparent communication strategy, the media described the story as a minor incident that was in the process of being fixed, rather than as a severe threat to public health. In describing the NDMA problem, the Los Angeles Times reported: 
"NDMA [...] is a ubiquitous chemical that occurs naturally, but also is a byproduct of chlorinating water supplies to disinfect them. It is found in rocket fuel, pesticides, lubricants, cosmetics, and all kinds of food, from bacon to beer and at far higher levels than turned up in local water tests... There is believed to be no threat to public health, district officials said." 43

Overall, OCWD's Type 1 legitimation activities addressed all relevant subdimensions. They successfully educated people about the need for potable reuse and convinced them potable water reuse would meet their needs more effectively than the alternatives; they engaged community members in improving outreach by addressing public concerns about potable reuse; and they proved that the OCWD was transparent and proactively engaged in serving the public interest (Interview 2).

Type 2. Moral Legitimacy. Many of OCWD's activities promoted Type 2 legitimation by embedding potable water reuse into wider moral belief systems. First, OCWD used its long experience with potable water reuse (through injection of treated wastewater into the aquifer) and its reputation in the community to establish consequential legitimacy, or faith in the organization's capacity to responsibly conduct potable reuse (Interview 12). When the utility introduced plans to expand their potable reuse system in the late 1990s, they could show the public a three-decade-long track record of safe and reliable operations:

"[OCWD] already had that plant running, they were operating it, they were doing all the monitoring. They had developed a reputation. They developed the confidence of the community... Once they wanted to expand, they were expanding on a base of success and reputation." (Interview 20)

Regular testing for a suite of contaminants at OCWD also became an important element of creating procedural legitimacy. When confronted with a complex, new technology the public often forms opinions about it by asking whether the organization running it is applying the right procedures to guarantee safety. ${ }^{28}$ OCWD was addressing this issue by establishing strict water quality testing procedures and monitoring for 335 chemicals, instead of just the 122 compounds required of them by the regulator. 44

In addition, OCWD developed standard operating procedures for their water reuse system. They established protocols for routine operating conditions and in the event of an upset and explained these to end users in tours (Interview 1). In addition to providing clarity to the plant's operators, this further improved procedural legitimacy of the organization.

Third, OCWD consistently emphasized that it had the right physical infrastructure in place to guarantee safe operations (structural legitimacy). Other professionals were impressed with how the utility maintained cutting-edge technologies for water treatment and source control, employed more than 200 staff, operated $24 / 7$ and built a state-of-the-art water quality laboratory directly on-site (Interviews 1, 2, 15). Interviews reveal the existence of a lab inside the utility was effective in signaling structural legitimacy to the general public (Interview 17).

OCWD's management staff also reinforced personal legitimacy by personally speaking to the public in outreach campaigns:

"It wasn't the consultants who did the speeches. It was staff or board members. We found that the people, the general public, gravitate much more to the personal touch, when it's someone actually affiliated with the project." (Interview 19)

In doing so, OCWD managers established themselves with members of the public as trustworthy and competent experts
(Interview 16) who could handle the complex water reuse system.

Type 3. Cognitive Legitimacy. OCWD worked to deliberately establish Type 3 legitimacy. OCWD's choice of name for their potable water reuse technology, the "Groundwater Replenishment System," made the public associate what the utility was doing with Orange County's half-century-long practice of augmenting groundwater with fresh water in order to prevent saltwater intrusion into the aquifer, rather than with a new, unfamiliar technology (Interview 12). The name "Groundwater Replenishment System" had positive cognates to protecting groundwater from contamination and ensuring a safe water supply, and was a familiar reference to end users, thus improving the comprehensibility of the project. West Basin Water District also adopted this strategy to enhance comprehensibility, calling the agency that injected recycled water back into the aquifer the "Water Replenishment District" (Interview 4).

Second, OCWD tried to mesh the idea of potable water reuse with frames ${ }^{45}$ that were taken-for-granted by their constituents. Use of the term "water recycling" exemplified this effort; framing the GWRS as potable "reuse" and water "recycling" (Interview 4) allowed OCWD to enlist the support of environmentalists who were favorably disposed toward recycling in general:

"The first groups to be supportive were environmental groups.

I think they saw recycling as just making good environmental

ethical sense, so they were supportive early on." (Interview 19)

As a result of these comprehensive efforts, potable water reuse reached a level of legitimacy in Orange County that made it improbable that voices of opposition would gain traction within the community. ${ }^{3}$ Available evidence suggests that local media is not particularly interested in the OCWD's water reuse project anymore because it has become routine (Interviews 19, 20).

OCWD is one of a limited number of utilities that have successfully introduced potable water reuse. Other utilities that have achieved a similar level of legitimacy include the West Basin Municipal Water District and Inland Empire Utilities Agency. ${ }^{5}$ When managers of West Basin Municipal Water District began their potable water reuse project, they mimicked both OCWD's technology and outreach approach, which they institutionalized by hiring some of OCWD's experienced personnel (Interviews 4, 10).

Legitimation Portfolio of Other Utilities in California's Water Reuse Sector. Despite the legitimacy of the potable reuse projects in Orange County, West Basin, and the Inland Empire, public opposition has halted similar projects at the Upper San Gabriel Water District, the City of San Diego, Dublin-San Ramon Services District (DSRSD), and the City of Los Angeles. In response to these failed projects, an advocacy coalition of utilities, consulting engineering firms, academia and NGOs has emerged to work toward legitimizing potable water reuse in general., ${ }^{3,46}$ Internal networks like the WateReuse Association and the National Water Research Institute ${ }^{3}$ increasingly coordinate legitimation strategies and recently began lobbying the state government to streamline the implementation of direct potable water reuse policies (i.e., potable water reuse without an intervening natural barrier like an aquifer or a lake). ${ }^{47}$ The process is described in more detail in another publication. ${ }^{3}$ In the following section, we use the legitimacy framework to analyze the legitimation strategies that have been used by failed potable reuse projects as well as by the coalition of proponents of potable water reuse.

Type 1. Pragmatic Legitimacy. The cases of several proposed potable reuse projects that were halted by public opposition 
in the 1990s show that a lack of exchange legitimacy can spur public resistance to potable water reuse (Interviews 7, 20). An illustrative example is a potable reuse system in Dublin-San Ramon Services District (DSRSD) that was halted by public opposition. In retrospect, experts close to the project believed that DSRSD's board made a mistake by advertising their potable reuse project as a wastewater management strategy, rather than as an improvement in drinking water supply (Interviews 12, 20). The result was a lack of exchange legitimacy for water users-only wastewater managers, and not the general public, could see a direct benefit from the potable water reuse system.

In addition, what water managers touted as a benefit of the recycled water in the Dublin-San Ramon area-that it would enable economic growth and suburban development, an argument that seemed to have worked in Orange Countywas not favorably received in the Northern California social context (Interview 20). Public opposition quickly emerged in the Dublin-San Ramon area as groups questioned whether there was an actual need to make the public "drink wastewater". A local newspaper, the Pleasanton Weekly, reported:

"DSRSD representatives said they need to have a way to dispose of treated wastewater if and when it exceeds the capacity of the LAVWMA pipeline. "We're not in love with injection," said DSRSD board director Georgean VonheederLeopold, "It's just that it makes the most sense... and it's economical that way. We just don't want to put it in the creek or irrigate with it." ${ }^{\prime 4}$

Potable water reuse advocacy coalitions subsequently funded several research projects on ways to improve exchange legitimacy for potable reuse (Interview 7$).{ }^{49}$ Research results suggested that framing planned potable reuse as an improvement over existing water supplies, many of which employ de facto reuse (i.e., a practice in which water from a municipal wastewater treatment plant discharges into a river or lake that is used as the drinking water source for a downstream community $)^{5}$ was an effective means of increasing exchange legitimacy and public support. ${ }^{46,50}$ In conjunction with the research projects, the WateReuse Association created an educational video, called "Downstream," to explain de facto water reuse and try to create exchange legitimacy for the broader potable water reuse sector. ${ }^{50,51}$

Some water agencies have begun to integrate elements of influence legitimacy into outreach campaigns. Recent potable water reuse projects in West Basin, San Diego, and Santa Clara employed focus groups to address public concerns (Interview 4). Despite these efforts, many water utilities only allow limited public involvement in planning and decision-making. Water managers often lack a commitment to implementing suggestions raised by focus group participants (Interview 7), effectively negating their efforts to establish influence legitimacy for potable reuse projects.

"[Water utility managers] talk about public involvement.

They don't really want involvement, because they know what

they want to do, and they want to just go do it and want everybody to like it." (Interview 16)

Many water utilities also did not focus on dispositional legitimacy as part of their legitimation strategy. For example, opposition to Dublin-San Ramon Services District's proposed potable reuse project cited a lack of trust in the organization's integrity and the utility's "maverick" reputation, which stemmed from its perceived support of a controversial suburban expansion project (Interview 20). A passionate editorial in the local newspaper about the ballot measure to implement potable reuse further demonstrates this lack of trust in the utility:
"Why would we trust the stewardship of our most precious resource to a sewer company?... The proponents of this measure have intentionally tried to mislead the public into thinking this is a vote for recycling. Their slick propaganda campaign has been less than straightforward... Why would we trust them to be forthcoming if an accident or human error occurred that permanently contaminated our groundwater basin?"52

To address the poor image of water and wastewater utilities like DSRSD, advocates for potable water reuse in Southern California began collaborating to improve water and wastewater agencies' reputation, and thereby their dispositional legitimacy, by creating a "utility branding network" in 2007.53 The network's activities focused on competitive branding strategies at the regional potable water reuse sector-wide scale ${ }^{54}$ in an attempt to show utilities how to avoid the type of resistance which DSRSD met. Building trust in a utility is a long-term process and it is difficult to assess whether the utility branding network has improved dispositional legitimacy for water and wastewater utilities in California.

Type 2. Moral Legitimacy. Several projects with long-term track records like Orange County and West Basin have shown that potable reuse systems can be operated to meet water quality regulations and provide benefits in terms of water supply and wastewater disposal to communities, resulting in consequential legitimacy. Proponents of water reuse often reference these examples. However, existing water reuse advocacy coalitions and many water and wastewater utilities in California did not emphasize other key dimensions of Type 2 legitimacy.

Procedural Legitimacy is a case in point: Water utility managers and consultants have invested in research and development related to the operation of specific engineered treatment trains, but few resources have been devoted to developing sectorwide procedures to ensure safe water reuse operations. Experts within the potable water reuse sector have identified the need for a number of sector-wide procedural standards, ${ }^{55}$ including regulatory oversight, ${ }^{56}$ operator training (Interview 1), source control (Interview 4), and emergency procedures (Interview 5). Currently, responsibility for developing these procedures falls on individual water utility managers on an ad-hoc basis (Interviews $6,14)$. To address this apparent shortcoming, the WateReuse Foundation has recently initiated a project to develop training and certification schemes for utilities that run direct potable reuse plants. ${ }^{4,47,57}$ The development and diffusion of such standards may improve procedural legitimacy for potable water reuse.

Structural Legitimacy, in contrast, has recently become a strong current focus of the potable water reuse community. Experts in academia, engineering consulting groups, and industry have been working to develop cutting-edge technologies to improve treatment processes, monitor systems online, or engineer buffers that extend response time in case of system failures. ${ }^{12,46,47,58-60}$ Currently, no clear structural standards exist for potable reuse systems. Due to the lack of public opposition to its project, OCWD's treatment train for potable reuse has developed into an unofficial sector-wide best practice (Interview 1), which has been replicated in several new projects.

Personal Legitimacy, finally, was not an important element in many contentious potable reuse projects. In some cases, the managers of the utility lacked the public speaking experience or interest in serving as public communicators about potable reuse (Interview 16). In an attempt to get charismatic leaders to speak publicly about potable reuse projects, some utilities attempted to enlist local politicians to speak in support (Interview 8)-yet this 
strategy sometimes backfired when politicians neared the ends of their terms and actively tried to garner votes by appealing to public sentiments against potable reuse (Interview 18).

Type 3. Cognitive Legitimacy. Following public opposition to potable reuse projects in the $1990 \mathrm{~s}$, advocacy coalitions for potable reuse have begun to address comprehensibility by improving education activities and adapting them to different audiences (Interview 7). Some water agencies strategically dispatched people to conduct outreach programs whose racial background matched that of the communities they spoke with "There are [utilities] who hire a Latino consultant to work with the Latino community, hire an Asian-American consultant to work with the Asian-American community, hire an African-American consultant, because then people are hearing this from people who look like them, who've had similar experiences." (Interview 16)

Advocates for potable water reuse also developed vocabulary and imagery that related potable reuse to positively connote cognitive frames like "recycling", and attempted to standardize these terms across engineers and utilities advocating for potable reuse (Interview 7). ${ }^{14}$ While environmentalists tend to oppose desalination projects, ${ }^{61}$ in part because of a perception that creating new water sources in arid regions will encourage growth in areas that ecologically cannot support an increasingly large population, they tend to support water recycling because it ties in with their ideals of living in closed-loop systemsthough potable water reuse projects also effectively create a new water source that could have the same growth effect in waterscarce regions (Interview 11).

In addition, the WateReuse Foundation employed surveys and focus groups to understand which vocabulary words and images would resonate well with cognitive frames of water users. They found that wording related to the origin of the water (i.e., wastewater, sewage, treated wastewater) resonated poorly, whereas terms that emphasize the high quality of the produced water (e.g., purified water) were more acceptable. ${ }^{14}$ However, proponents of potable reuse at different water utilities continue to use a variety of terms to describe the practice (Interviews 7, 11).

Most potable water reuse projects in California have not reached a taken-for-granted level of legitimacy. Advocacy coalitions for potable water reuse have begun to implicitly address this issue, mainly through describing potable water reuse as part of the natural water cycle (Interview 7), and by framing potable reuse as "water recycling," which associates the practice with the taken-forgranted frame of converting something used into something new and fresh. See Table 3.

\section{DISCUSSION}

Several key observations stand out when comparing legitimacy of potable water reuse at OWCD and other potable water reuse projects in California. First, a legitimacy framework for assessing potable water reuse projects, in combination with an understanding of the history and values of local residents in the project area, appears to be useful in explaining adoption of potable water reuse. OCWD's success in establishing legitimacy for potable water reuse cannot be ascribed purely to its innovative technological approach or to its constituents' passive acceptance of expert opinion. OCWD employed a comprehensive portfolio of legitimation strategies both deliberately and by chance, which fostered public trust in the utility and in the practice of potable reuse.

When the practice of potable water reuse began to spread beyond OCWD, many engineers assumed building structurally
Table 3. Legitimation Portfolio of Other California Potable Reuse Projects ${ }^{a}$

\begin{tabular}{|c|c|c|}
\hline legitimacy & dimension & examples \\
\hline \multirow[t]{3}{*}{ Type 1: pragmatic } & 1.1 exchange & $\begin{array}{l}\text { + outreach campaigns to establish } \\
\text { controlled potable reuse as an } \\
\text { improvement over de facto reuse }\end{array}$ \\
\hline & 1.2 influence & $\begin{array}{l} \pm \text { weak public involvement in } \\
\text { planning and decision-making } \\
\text { about potable reuse }\end{array}$ \\
\hline & 1.3 dispositional & $\begin{array}{l}\text { - little proof of the sector's "good } \\
\text { character", despite branding } \\
\text { efforts }\end{array}$ \\
\hline \multirow[t]{4}{*}{ Type 2: moral } & 2.1 consequential & $\begin{array}{l}+ \text { successful track record with } \\
\text { indirect potable reuse systems in } \\
\text { some places }\end{array}$ \\
\hline & 2.2 procedural & $\begin{array}{l}\text { - incomplete procedural standards } \\
\text { for water reuse plants }\end{array}$ \\
\hline & 2.3 structural & $\begin{array}{l}+ \text { research on infrastructure and } \\
\text { technology development }\end{array}$ \\
\hline & 2.4 personal & $\begin{array}{l} \pm \text { few knowledgeable } \\
\text { spokespersons for potable reuse }\end{array}$ \\
\hline \multirow[t]{3}{*}{ Type 3: cognitive } & $\begin{array}{l}3.1 \\
\text { comprehensibility }\end{array}$ & $\begin{array}{l}+ \text { development of vocabulary that } \\
\text { meshes with cognitive frames }\end{array}$ \\
\hline & & - inconsistent use of terminology \\
\hline & $\begin{array}{l}3.2 \text { taken-for- } \\
\text { grantedness }\end{array}$ & $\begin{array}{l} \pm \text { relating potable reuse to the } \\
\text { water cycle }\end{array}$ \\
\hline
\end{tabular}

sound treatment and monitoring systems would suffice for establishing public trust in potable reuse. This approach did create structural legitimacy, but this attribute could not compensate for other shortcomings in the legitimacy portfolio such as the lack of community representation in decision-making and the lack of trust in the utility's ability to manage risk. These experiences show that potable reuse projects seeking societal legitimacy cannot establish it by simply copying the treatment train from OCWD; they must also adopt a comprehensive legitimation portfolio approach.

In contrast to OCWD, many other potable water reuse projects in California have had substantial gaps in their legitimation portfolios. Overall, proponents of potable reuse have often categorized opposition to potable water reuse in a narrow technology-focused and social-marketing-based "public acceptance" paradigm. Important gaps in the legitimation portfolio occur if this paradigm is used-dispositional and procedural legitimacy, and to a lesser degree influence and personal legitimacy, are usually absent. Sociological theory and our interviewees identified the importance of covering these dimensions if potable reuse is to attain a "taken-for-granted" level of legitimacy. This need becomes even more pertinent when considering the recent advocacy efforts for direct potable reuse, which is likely to provoke wider attention and therefore additional questions on whether the current industry is "right for the job."

For potable water reuse to be legitimate, potable water reuse projects must demonstrate how they will benefit the end users of the water (exchange legitimacy), strengthen public involvement in planning and decision-making (influence legitimacy), incorporate transparent communication procedures and develop an organizational reputation for high quality (dispositional legitimacy), and have reliable risk management procedures and emergency intervention procedures in place (procedural legitimacy). The legitimacy portfolio also requires involvement 
of experienced utility managers in public outreach (personal legitimacy) and relation of potable reuse to established social practices (taken-for-grantedness).

The current lack of standardized operational procedures for potable water reuse systems is especially striking. Training and certification programs specific to potable water reuse operators, with creation of a sector-wide standard, could be useful for establishing procedural legitimacy. A promising strategy might be to emulate risk management and emergency procedures from similar low-probability, high-consequence industries like aviation. The oversight of an independent, possibly governmental organization to investigate system failures, similar to the Federal Aviation Administration and the National Transportation Safety Board, could be beneficial for establishing procedural legitimacy. This would make the innovation more understandable by relating it to standards and procedures that have already gained legitimacy in other established sectors.

The legitimacy portfolio perspective presented in this paper is relevant beyond the California potable water reuse case. It can be applied to potable reuse systems worldwide, to other innovations in the water sector (e.g., point-of-use treatment or onsite water recycling) or potentially to innovation in other sectors, like energy or transportation. Our findings suggest that establishment of legitimacy for an innovation like potable water reuse relies upon a balanced and comprehensive portfolio of strategies that address all three types of legitimacy. These legitimation strategies include elements like collaborative public engagement in planning and decision-making, which are outside the realm of the "public acceptance" paradigm traditionally employed in water projects. A fourth type of legitimacy, regulatory legitimacy, ${ }^{31}$ has not been explicitly separated in this research from the other three types. The role of regulatory legitimacy in potable water reuse merits future research.

These findings do not imply that there will never be opposition to potable water reuse projects if all legitimacy dimensions are addressed. In fact, potable water reuse may turn out not to be legitimate in some communities, especially if it does not satisfy the community's criteria for meeting all three aspects of legitimacy, and other options for water supply and/or wastewater disposal may be more appropriate. Rather, the broader the legitimacy portfolio, the lower the probability that potable water reuse projects will move forward to a level of financial investment in physical infrastructure in places where opposition to the project will prevent it from coming to fruition. These results also show that many dimensions of legitimacy cannot be created by changes in vocabulary or promotional campaigns alone, which are hallmarks of marketing in a public acceptance paradigm. Establishing legitimacy may require wide-ranging structural, procedural or institutional changes, which ideally emulate prelegitimized practices from other sectors.

It is important to note that ideas of legitimacy are culturally specific. What constitutes exchange legitimacy in one place may not be considered valid elsewhere. For example, having more water to enable suburban growth was legitimate in southern California but it helped create opposition to the Dublin San Ramon water reuse project in northern California. Also, this analysis focused on legitimacy among members of the general public, mainly in an attempt to complement existing acceptance studies. Legitimation strategies to engage other groups (e.g., politicians, regulators or experts) might be equally important and should be addressed in future studies. Future research to survey potential potable water reuse users with regard to pragmatic, moral, and cognitive legitimacy in contemporary cases of utilities considering implementation of potable water reuse would be useful to supplement the historical perspective given here. Finally, the present case studies should be complemented with research in other sectors like energy or transportation to improve the concept's generalizability.

\section{ASSOCIATED CONTENT}

\section{S Supporting Information}

The Supporting Information is available free of charge on the ACS Publications website at DOI: 10.1021/acs.est.5b00504.

\section{AUTHOR INFORMATION}

\section{Corresponding Author}

*Phone: (510) 642-1640; fax: (510) 642-1085; e-mail: sharrislovett@berkeley.edu.

\section{Notes}

The authors declare the following competing financial interest(s): The authors of this paper are affiliated with the Engineering Research Center for Re-Inventing the Nation's Urban Water Infrastructure (ReNUWIt), which has an Industrial Advisory Board that provides advice on strategic research direction and includes organizations represented by interviewees in the study. ReNUWIt also receives membership funding (between $\$ 2,000$ and $\$ 25,000$ per year) from all Industrial Advisory Board members, including organizations represented by interviewees in the study. One of the authors of this paper (D.L.S.) was awarded a $\$ 50,000$ honorarium for receiving the Clarke Prize in 2014 by the National Water Research Institute, one of the interview partners in the study.

\section{ACKNOWLEDGMENTS}

We thank our interviewees for their time and candid responses. Empirical research was conducted in accordance with provisions of protocols reviewed by the UC Berkeley Committee for the Protection of Human Subjects. This work was partially conducted while one of the authors was a Giorgio Ruffolo PostDoctoral Fellow in the Sustainability Science Program at Harvard University. Support from Italy's Ministry for Environment, Land and Sea is gratefully acknowledged. This research was supported by a National Science Foundation Graduate Research Fellowship (to SHL), by the Swiss Federal Institute for Aquatic Sciences (Eawag) and by the National Science Foundation's Engineering Research Center for Reinventing the Nation's Urban Water Infrastructure (ReNUWIt), EEC-1028268.

\section{REFERENCES}

(1) Brown, R. R.; Keath, N.; Wong, T. H. F. Urban water management in cities: Historical, current and future regimes. Water Sci. Technol. 2009, 59 (5), 847.

(2) Kiparsky, M.; Sedlak, D. L.; Thompson, B. H.; Truffer, B. The innovation deficit in urban water: The need for an integrated perspective on institutions, organizations, and technology. Environ. Eng. Sci. 2013, 30 (8), 395-408.

(3) Binz, C.; Sedlak, D. L.; Harris-Lovett, S.; Kiparsky, M.; Truffer, B. Legitimizing disruptive innovation-How support of potable water reuse was constructed in California. Technol. Forecast. Soc. Change, accepted.

(4) Bischel, H. N.; Simon, G. L.; Frisby, T. M.; Luthy, R. G. Management experiences and trends for water reuse implementation in northern California. Environ. Sci. Technol. 2012, 46 (1), 180-188.

(5) National Research Council (US). Committee on the Assessment of Water Reuse as an Approach for Meeting Future Water Supply Needs. In Water Reuse: Potential for Expanding the Nation's Water 
Supply Through Reuse of Municipal Wastewater; National Academies Press, 2012.

(6) National Research Council. Issues in Potable Reuse: The Viability of Augmenting Drinking Water Supplies with Reclaimed Water; National Academies Press, 1998.

(7) Cain, C. R. An Analysis of Direct Potable Water Reuse Acceptance in the United States: Obstacles and Opportunities. MPH thesis, John Hopkins Bloomberg School of Public Health: Baltimore, MD, 2011.

(8) Leverenz, H. L.; Tchobanoglous, G.; Asano, T. Direct potable reuse: A future imperative. J. Water Reuse Desalination 2011, 1 (1), 2. (9) Schroeder, E.; Tchobanoglous, G.; Leverenz, H.; Asano, T. Direct Potable Reuse: Benefits for Public Water Supplies, Agriculture, the Environment, and Energy Conservation: An NWRI White Paper, NWRI2012-01; National Water Research Institute, 2012.

(10) Daigger, G. T. Evolving urban water and residuals management paradigms: Water reclamation and reuse, decentralization, and resource recovery. Water Environ. Res. 2009, 81 (8), 809-823.

(11) Hurlimann, A.; Dolnicar, S. When public opposition defeats alternative water projects-The case of Toowoomba Australia. Water Res. 2010, 44 (1), 287-297.

(12) Wade Miller, G. Integrated concepts in water reuse: Managing global water needs. Desalination 2006, 187 (1-3), 65-75.

(13) Nellor, M. H.; Millan, M. Public and Political Acceptance of Direct Potable Water Reuse, WateReuse California Direct Potable Reuse Workshop, April 26, 2010.

(14) Macpherson, L.; Slovic, P. Talking about Water: Vocabulary and Images that Support Informed Decisions about Water Recycling and Desalination, WRRF 07-03; WateReuse Research Foundation, 2011.

(15) Stenekes, N.; Colebatch, H. K.; Waite, T. D.; Ashbolt, N. J. Risk and governance in water recycling public acceptance revisited. Sci. Technol. Hum. Values 2006, 31 (2), 107-134.

(16) Haddad, B.; Rozin, P.; Nemeroff, C.; Slovic, P. The Psychology of Water Reclamation and Reuse: Survey Findings and Research Roadmap; WateReuse Foundation: Alexandria, VA, 2009.

(17) Dolničar, S.; Saunders, C. Recycled water for consumer markets-A marketing research review and agenda. Desalination 2006, 187 (1-3), 203-214.

(18) Dolnicar, S.; Hurlimann, A. Water alternatives-Who and what influences public acceptance? J. Public Aff. 2011, 11 (1), 49-59.

(19) Dolnicar, S.; Schäfer, A. I. Desalinated versus recycled water: Public perceptions and profiles of the accepters. J. Environ. Manage. 2009, 90 (2), 888-900.

(20) Hurlimann, A.; Dolnicar, S.; Meyer, P. Understanding behaviour to inform water supply management in developed nations-A review of literature, conceptual model and research agenda. J. Environ. Manage. 2009, 91 (1), 47-56.

(21) Khan, S. J.; Gerrard, L. E. Stakeholder communications for successful water reuse operations. Desalination 2006, 187 (1), 191202.

(22) Nancarrow, B. E.; Leviston, Z.; Po, M.; Porter, N. B.; Tucker, D. I. What drives communities' Decisions and behaviours in the reuse of wastewater. Water Sci. Technol. 2008, 57 (4), 485-492.

(23) Marks, J. S. Taking the public seriously: The case of potable and non potable reuse. Desalination 2006, 187 (1-3), 137-147.

(24) Russell, S.; Lux, C.; Hampton, G. Beyond "Information": Integrating consultation and education for water recycling initiatives. Soc. Nat. Resour. 2008, 22 (1), 56-65.

(25) Bell, S.; Aitken, V. The socio-technology of indirect potable water reuse. Water Sci. Technol. Water Supply 2008, 8 (4), 441.

(26) Pinkham, R. 21st Century Water Systems: Scenarios, Visions, and Drivers; Rocky Mountain Institute: Snowmass, CO, 1999.

(27) Markard, J.; Wirth, S.; Truffer, B. Institutional Dynamics and Technology Legitimacy - A framework and a case study of biogas technology. Res. Policy accepted.

(28) Suchman, M. C. Managing legitimacy: Strategic and institutional approaches. Acad. Manage. Rev. 1995, 20 (3), 571-610.

(29) Geels, F. W.; Verhees, B. Cultural legitimacy and framing struggles in innovation journeys: A cultural-performative perspective and a case study of Dutch nuclear energy (1945-1986). Technol. Forecast. Soc. Change 2011, 78 (6), 910-930.

(30) Johnson, C.; Dowd, T. J.; Ridgeway, C. L. Legitimacy as a social process. Annu. Rev. Sociol. 2006, 53-78.

(31) Scott, W. R. Institutions and Organizations: Ideas and Interests, 3rd ed..; SAGE Publications, Inc: Los Angeles, 2008.

(32) Lawrence, T. B.; Suddaby, R.; Leca, B. Institutional Work: Actors and Agency in Institutional Studies of Organizations, Reissue ed.; Cambridge University Press: Cambridge, 2011.

(33) Harris-Lovett, S.; Sedlak, D. L. The history of water reuse in California. In Sustainable Water: Challenges and Solutions from California; Lassiter, A., Ed.; University of California Press: Berkeley, $\mathrm{CA}$, in press.

(34) Allen, P. K.; Elser, G. L. They said it couldn't be done - the orange County, California experience. Desalination 1979, 30 (1), 2338.

(35) Orange County Water District: Historical Information http:// www.ocwd.com/About/HistoricalInformation.aspx (accessed July 25, 2014).

(36) Argo, D. G. Water reuse: Where are we headed? Environ. Sci. Technol. 1985, 19 (3), 208-214.

(37) Markus, M. R.; Deshmukh, S. S. An innovative approach to water supply-The groundwater replenishment system. World Environmental and Water Resources Congress 2010, 3624-3639.

(38) Heckathorn, D. D. Respondent-driven sampling: A new approach to the study of hidden populations. Soc. Probl. 1997, 44 (2), 174-199.

(39) Atkinson, R.; Flint, J. Accessing hidden and hard-to-reach populations: Snowball research strategies. Soc. Res. Update 2001, 33 (1), 1-4.

(40) Ching, L.; Yu, D. J. Turning the tide: Informal institutional change in water reuse. Water Policy 2010, 12 (S1), 121-134.

(41) Geels, F. W.; Verhees, B. Cultural legitimacy and framing struggles in innovation journeys: A cultural-performative perspective and a case study of Dutch nuclear energy (1945-1986). Technol. Forecast. Soc. Change 2011, 78 (6), 910-930.

(42) Mitch, W. A.; Sharp, J. O.; Trussell, R. R.; Valentine, R. L.; Alvarez-Cohen, L.; Sedlak, D. L. N-Nitrosodimethylamine (NDMA) as a drinking water contaminant: A review. Environ. Eng. Sci. 2003, 20 (5), 389-404.

(43) Mehta, S. Water District Closes 2 Wells Contaminated by Chemical; Wells in Costa Mesa and Huntington Beach had excessive levels of suspected carcinogen. Officials say there is no threat to public health. [Orange County Edition]. Los Angeles Times. Los Angeles, California, United States, June 1, 2000; p 1.

(44) Water Quality and Laboratory Operations http://www.ocwd. com/ProgramsProjects.aspx (accessed September 9, 2014).

(45) Lakoff, G. Why it matters how we frame the environment. Environ. Commun. J. Nat. Cult. 2010, 4 (1), 70-81.

(46) Ruetten, J. Best Practices for Developing Indirect Potable Reuse Project: Phase 1 Report, WRF-01-004; WateReuse Foundation: Alexandria, VA, 2004.

(47) Tchobanoglous, G.; Leverenz, H.; Nellor, M. H.; Crook, J. Direct Potable Reuse: A Path Forward; WateReuse Association, 2011.

(48) Ericson, S. Pleasanton, DSRSD work towards RO agreement. Pleasanton Weekly (online edition). Pleasanton, California June 30, 2000,.

(49) Ruetten, J. Understanding Public Concerns and Developing Tools for Potable Reuse Projects; 2919; Awwa Research Foundation, 2006.

(50) WateReuse Research Foundation. Effect of Prior Knowledge of Unplanned Potable Reuse on the Acceptance of Planned Potable Reuse, Downstream: Research to Shift Community Attitudes on Water Reuse; WRF-09-01; WateReuse Research Foundation, 2012.

(51) WateReuse Association. Downstream, 2012.

(52) Vote on Measure J: Pleasanton not ready for RO treatment. Pleasanton Weekly (online edition). Pleasanton, California February 18, 2000,

(53) Utility Branding Network homepage http://utilitybranding.net/ index.php (accessed September 10, 2014). 
(54) Ruetten, J. Building the Wastewater Utility Brand: Practical Advice for Increasing Trust, Support and Investment; Southern California Alliance of Publicly Owned Treatment Works: Escondido, CA, 2008.

(55) Hultquist, B. Direct Potable Reuse: A Drinking Water Regulator's View; Workshop for the NWRI Panel Examining the Criteria for Direct Potable Reuse, Monterey, CA, 2013.

(56) Crook, J. Regulatory Aspects of Direct Potable Reuse in California: An NWRI White Paper, NWRI-2010-01; National Water Research Institute, 2010.

(57) WateReuse Research Request for Proposals: Development of Operation and Maintenance Plan and Training and Certification Framework for Direct Potable Reuse (DPR) Systems, WRRF-13-13; WateReuse Research Foundation, 2014.

(58) Drewes, J. Rejection of Wastewater-Derived Micropollutants in High-Pressure Membrane Applications Leading to Indirect Potable Reuse, 02-001-01; WateReuse Research Foundation, 2006.

(59) Trussell, R. R. Potable Reuse: State of the Science Report and Equivalency Criteria for Treatment Trains, 11-02-2; WateReuse Research Foundation, 2012.

(60) Serna, M.; Trussell, R. Shane; Gerringer, F. Ozone Pretreatment of a Non-Nitrified Secondary Effluent Before Microfiltration. 10-11-1; WateReuse Research Foundation, 2014.

(61) Dolnicar, S.; Hurlimann, A. Desalinated versus recycled water: What does the public think? Sustainable Sci. Eng. 2010, 2, 375-388. 